\title{
Adaptabilidade e estabilidade fenotípica de cultivares de café arábica em Minas Gerais
}

\author{
Cesar Elias Botelho(1), Juliana Costa de Rezende(1), Gladyston Rodrigues Carvalho(1), \\ Alex Mendonça de Carvalho(2), Vinicius Teixeira Andrade ${ }^{(3)}$ e Cintia Reis Barbosa ${ }^{(2)}$
}

\begin{abstract}
(1)Empresa de Pesquisa Agropecuária de Minas Gerais, Unidade Regional do Sul de Minas, Campus da Universidade Federal de Lavras (Ufla), s/no, Caixa Postal 176, CEP 37200-000 Lavras, MG. E-mail: cesarbotelho@epamig.br, julianacosta@epamig.br, carvalho@epamig.ufla.br (2)Ufla, Departamento de Agronomia, Caixa Postal 3.037, CEP 37200-000 Lavras, MG. E-mail: carvalho.am@hotmail.com, cynthia.reis87@gmail.com ${ }^{(3)}$ Ufla, Departamento de Biologia. E-mail: viniciusandrade84@yahoo.com.br
\end{abstract}

Resumo - O objetivo deste trabalho foi avaliar a adaptabilidade e a estabilidade fenotípicas para a produtividade de cultivares de cafeeiro do grupo Catuaí, pela metododologia de Annicchiarico. Foram instalados e conduzidos experimentos em Três Pontas, Campos Altos e Capelinha, em Minas Gerais. O delineamento foi o de blocos ao acaso, com quatro repetições e seis plantas por parcela. Os tratamentos foram constituídos por 15 cultivares do grupo Catuaí e cinco testemunhas. As avaliações da produtividade foram realizadas em seis colheitas nas safras de 2003/2004 a 2008/2009. Posteriormente, foi realizada a análise conjunta dos três locais e a avaliação da adaptabilidade e da estabilidade das cultivares. Na safra 2008/2009, foi avaliado o percentual de frutos chochos e a percentagem de grãos em peneira alta. As cultivares Catuaí Vermelho IAC 15, Catuaí Amarelo IAC 30, Catuaí Amarelo IAC 62 e Catuaí Vermelho IAC 72 são mais promissoras, pois aliam maiores estabilidade e adaptabilidade em ambientes favoráveis e desfavoráveis com alta média de produtividade. As cultivares Catuaí Vermelho IAC 100, Catuaí Amarelo IAC 86, Rubi MG 1192 e Catuaí Vermelho IAC 144 têm o mais alto percentual de peneira alta. Todas as progênies têm baixo percentual de grãos chochos.

Termos para indexação: Coffea arabica, cultivar Catuaí, frutos chochos, peneira alta, produtividade.

\section{Adaptability and phenotype stability of Arabica coffee cultivars in Minas Gerais, Brazil}

\begin{abstract}
The objective of this work was to evaluate the phenotypic adaptability and stability for grain yield of the Catuaí group of coffee cultivars by the method Annicchiarico. The experiments were installed and carried out in the counties of Três Pontas, Campos Altos and Capelinha, Minas Gerais state, Brazil. The experiments were carried out in a randomized complete block design, with four replicates and six plants per plot. The treatments were constituted by 15 cultivars of the Catuaí group and five controls. The grain yield evaluations were performed in the six harvests from 2003/2004 to 2008/2009 growing seasons. Then, the joint analysis of the three localities and the evaluation of cultivars adaptability and stability were performed. The parameters floating beans and high sieve grains were carried out considering the 2008/2009 harvest. The cultivars Catuaí Vermelho IAC 15, Catuaí Amarelo IAC 30, Catuaí Amarelo IAC 62 and Catuaí Vermelho IAC 72 were the most promising because they allied higher stability and adaptability in favorable and unfavorable environments with mean high yield. The cultivars Catuaí Vermelho IAC 100, Catuaí Amarelo IAC 86, Rubi MG 1192 and Catuaí Vermelho IAC 144 have the highest percentage of bean size grains. All the cultivars showed low percentage of floating grains.
\end{abstract}

Index terms: Coffea arabica, Catuaí cultivar, floating grains, high sieve grains, productivity.

\section{Introdução}

A cafeicultura brasileira tem experimentado melhorias decorrentes de pesquisas realizadas por várias instituições do país que se dedicam a esse fim, principalmente na área de melhoramento genético e desenvolvimento de novas cultivares, adaptadas às diferentes condições de cultivo e com características agronômicas superiores.

Entre as principais cultivares de café arábica (Coffea arabica L.), as do grupo 'Catuaí' têm se destacado pela elevada adaptação a diversas regiões. Originam-se

Pesq. agropec. bras., Brasília, v.45, n.12, p.1404-1411, dez. 2010 
do cruzamento artificial entre 'Caturra' e 'Mundo Novo', iniciado em 1949 no Instituto Agronômico de Campinas (IAC), com o objetivo de reunir as características de produtividade e rusticidade do 'Mundo Novo' com o porte reduzido de 'Caturra'. As cultivares oriundas desse cruzamento têm frutos de coloração amarela ou vermelha e maturação média, susceptibilidade à ferrugem e elevada adaptação a condições com e sem irrigação (Carvalho et al., 2008a).

Contudo, no Brasil, as regiões cafeeiras são bem distintas, cada uma com características ambientais definidas, que influenciam o comportamento das cultivares desenvolvidas. A resposta diferenciada de materiais genéticos a diferentes ambientes evidencia o que se conhece como interação genótipo-ambiente, o que indica que o comportamento dos genótipos é influenciado pelas condições ambientais (Cucolotto et al., 2007). Assim, um indivíduo que tenha comportamento superior, em um dado ambiente, pode não apresentar comportamento satisfatório quando sujeito a outras condições, e pode gerar prejuízos na atividade à qual está inserido.

Os componentes ambientais que influenciam essa interação genótipo-ambiente podem ser classificados em previsíveis, como manejo, práticas agronômicas e tipo de solo, e não previsíveis como oscilações de temperatura, ocorrência de pragas e doenças e intempéries climáticas (Vencovsky \& Barriga, 1992). Uma das maneiras mais utilizadas para minimizar o efeito dessa interação seria a realização de experimentos em locais contrastantes, com materiais genéticos promissores, para identificar os que apresentam ampla estabilidade e adaptabilidade (Yan et al., 2000; Cargnin et al., 2006). Essa opção identifica indivíduos de comportamento previsível e responsivos às variações ambientais, em condições específicas ou amplas.

$\mathrm{Na}$ cultura do café, são inúmeras as metodologias usadas para esse fim. Wamatu et al. (2003) evidenciaram a necessidade de se testar progênies, em várias localidades, para caracterização exata de seu desempenho, e classificaram, pelo uso de biplots do método AMMI, 21 clones de C. arabica avaliados em diferentes grupos de similaridade, baseados em seu desempenho e estabilidade fenotípica. Nascimento et al. (2010) avaliaram uma metodologia de análise de adaptabilidade e estabilidade fenotípica de genótipos de café, baseada em regressão não paramétrica, e demonstraram que ela é adequada e eficiente, pois extingue os efeitos impróprios induzidos pela presença de pontos extremos e evita a recomendação incorreta de genótipos quanto à adaptabilidade. Corrêa et al. (2006) avaliaram a adaptabilidade e estabilidade de progênies de cafeeiro, pelas metodologias Lin \& Binns (1988) e Annicchiarico (1992), e encontraram coerência de resultados.

O método não paramétrico de Annicchiarico (1992), estima a probabilidade de um genótipo apresentar desempenho superior ao de outros (Vasconcelos et al., 2010) e é indicado por Silva et al. (2008) por combinar adaptação, adaptabilidade e conceitos de estabilidade em somente um parâmetro, o que facilita a interpretação de resultados.

O objetivo deste trabalho foi avaliar cultivares do grupo Catuaí, em relação à adaptabilidade e estabilidade fenotípica da produtividade, pelo método deAnnicchiarico(1992), paraidentificar os genótipos de melhor comportamento frente às variações ambientais, nas regiões produtoras do Estado de Minas Gerais.

\section{Material e Métodos}

Os experimentos foram instalados em novembro de 2000, na Fazenda Experimental da Empresa de Pesquisa Agropecuária de Minas Gerais (Epamig), no Município de Três Pontas, na Fazenda Ouro Verde, em Campos Altos e na Fazenda Resplendor, em Capelinha. Esses locais representavam o Sul de Minas, Alto Paranaíba e Vale do Jequitinhonha, respectivamente, que são as principais regiões cafeeiras do Estado (Tabela 1).

Os experimentos foram instalados com 20 tratamentos, compostos do grupo Catuaí e cinco testemunhas: sete cultivares de Catuaí Amarelo (IAC 17, IAC 30, IAC 47, IAC 62, IAC 79, IAC 86, IAC 91), oito cultivares de Catuaí Vermelho (IAC 15, IAC 44, IAC 51, IAC 72, IAC 81, IAC 99, IAC 100, IAC 144) e cinco cultivares testemunhas (Topázio MG 1190, Rubi MG 1192, IAPAR 59, Mundo Novo IAC 502-9 e Acaiá Cerrado MG 1474). Foi utilizado o delineamento em blocos ao acaso, com quatro repetições, seis plantas por parcela, em que cada parcela foi representada pelas cultivares avaliadas.

O espaçamento adotado foi de $3,5 \times 0,50 \mathrm{~m}$, e a implantação e a condução dos experimentos foram feitas de acordo com as recomendações técnicas para a cultura do cafeeiro, usualmente empregadas na cultura para cada região (Reis \& Cunha, 2010), 
em que os tratos fitossanitários foram realizados acompanhando-se a sazonalidade da ocorrência das pragas e doenças.

As avaliações de produção foram efetuadas em seis colheitas consecutivas, nas safras 2003/2004 e 2004/2005 (biênio 1), 2005/2006 e 2006/2007 (biênio 2) e 2007/2008 e 2008/2009 (biênio 3). As parcelas foram colhidas, e a produção de litros de "café da roça" por parcela foi avaliada, anualmente, com a colheita realizada entre maio e julho de cada ano. Posteriormente, realizou-se a conversão do volume de café colhido para sacas de $60 \mathrm{~kg}$ de café beneficiado por hectare, por aproximação de valores, tendo-se considerado o rendimento médio de $480 \mathrm{~L}$ de "café da roça" para cada saca de $60 \mathrm{~kg}$ de café beneficiado, que corresponde ao rendimento médio adotado em todas as regiões (Carvalho et al., 2009).

A análise de variância conjunta foi realizada nos três locais e subdividida no tempo, e o conjunto de duas colheitas (biênio) foi considerado a subparcela. A combinação das colheitas em biênios melhora a precisão experimental, por reduzir os efeitos da bienalidade da produção (Bonomo et al., 2004; Botelho et al., 2010). A análise foi realizada após a constatação da homogeneidade das variâncias, por meio do teste de Hartley. Posteriormente, as médias foram comparadas pelo teste de Scott-Knott, a 5\% de probabilidade. Utilizou-se o aplicativo computacional Sisvar (Ferreira, 2008).

As análises de estabilidade e adaptabilidade foram realizadas, tendo-se considerado como ambientes as combinações de biênios com locais. Foi utilizada a metodologia proposta por Annicchiarico (1992), que propõe a adoção de um índice de confiança que estima o risco da adoção de determinado genótipo.
Os procedimentos para os cálculos pelo método proposto dão-se, inicialmente, com a transformação das médias de produtividade de cada cultivar em cada ambiente, em percentagem da média do ambiente. Posteriormente, estima-se a média $\mathrm{Y}_{\mathrm{i}(\mathrm{GFD})}$ e o desvio-padrão $\left(\mathrm{S}_{\mathrm{i}(\mathrm{GFD})}\right)$ das percentagens de cada cultivar para os ambientes de maneira geral (G), favoráveis $(\mathrm{F})$ e desfavoráveis (D).

Em seguida obtêm-se os índices de confiança $\mathrm{I}_{\mathrm{i}(\mathrm{GFD})}$ geral $(\mathrm{G})$, favoráveis (F) e desfavoráveis (D) para cada cultivar por meio do seguinte estimador:

$$
\mathrm{I}_{\mathrm{i}}=\mathrm{Y}_{\mathrm{i}}-\mathrm{Z}(1-\alpha) \mathrm{Si},
$$

em que: $\mathrm{I}_{\mathrm{i}}$ é o índice de confiança (\%); $\mathrm{Y}_{\mathrm{i}}$ é a média da cultivar i em percentagem; $Z$ é o valor na distribuição normal estandardizada, em que a função de distribuição acumulada atinge o valor percentual $(1-\alpha)$; e Si é o desvio-padrão dos valores percentuais. Quanto maior esse índice, menor o risco de adoção da cultivar. Foi utilizado o aplicativo computacional Genes (Cruz, 2006).

As avaliações de frutos chochos foram realizadas durante a colheita de 2009 , e as de peneira durante as colheitas de 2008 e 2009, ambas no Município de Três Pontas. A percentagem de frutos chochos foi realizada pela metodologia proposta por Antunes Filho \& Carvalho (1954), pela qual se colocam 100 frutos cereja em água, e são contabilizados como chochos aqueles que permanecem na superfície. A classificação do tamanho dos grãos foi realizada com amostras de $300 \mathrm{~g}$ de café beneficiado, avaliadas em peneiras intercaladas (Brasil, 2003). A percentagem de grãos chatos é resultante do somatório das peneiras $17 \mathrm{e}$ acima de 17 (peneira alta).

Tabela 1. Descrição das características de clima e solo dos três municípios de avaliação do trabalho.

\begin{tabular}{lccc}
\hline Característica & Três Pontas & Campos Altos & Capelinha \\
\hline Tipo de solo & Latossolo Vermelho distrófico & Latossolo Vermelho-Amarelo & Latossolo Vermelho-Amarelo húmico \\
Textura & distrófico & Argilosa \\
Relevo & Argilosa & Argilosa & Ondulado \\
Altitude & $900 \mathrm{~m}$ & Plano & $820 \mathrm{~m}$ \\
Latitude & $21^{\circ} 00^{\prime} 22^{\prime \prime} \mathrm{S}$ & $1.230 \mathrm{~m}$ & $21^{\circ} 40^{\prime} \mathrm{S}$ \\
Longitude & $45^{\circ} 30^{\prime} 45^{\prime \prime} \mathrm{W}$ & $19^{\circ} 41^{\prime} 47 " \mathrm{~S}$ & $45^{\circ} 55^{\prime} 00^{\prime \prime} \mathrm{W}$ \\
Temperatura média anual & $20,1^{\circ} \mathrm{C}$ & $46^{\circ} 10^{\prime} 17 " \mathrm{~W}$ & $21,3^{\circ} \mathrm{C}$ \\
Precipitação média anual & $1.670 \mathrm{~mm}$ & $17,6^{\circ} \mathrm{C}$ & $1.450 \mathrm{~mm}$ \\
\hline
\end{tabular}




\section{Resultados e Discussão}

Houve efeito estatísticamente significativo de produtividade de grãos para cultivares, locais, biênios e para as interações cultivares x locais, locais x biênios, cultivares x biênios, cultivares x locais x biênios (Tabela 2). A significância da interação mostra que o comportamento das cultivares não é coincidente nos ambientes avaliados. Ao se analisar cada local, observa-se que houve a formação de três grupos no Município de Três Pontas, com destaque para a cultivar Catuaí Vermelho IAC 72, com produtividade de 41,1 sacas ha-1, que superou todas as testemunhas (Tabela 3). Esses dados corroboram os de Melo et al. (2006) e de Andrade et al. (2007), que observaram que essa cultivar se destacou quanto à produtividade das cultivares de Catuaí, em Uberlândia, MG.

Em Campos Altos houve a formação de três grupos, dois deles com alto potencial produtivo. No grupo superior, composto por 11 cultivares mais as testemunhas Mundo Novo IAC 502-9 e Acaiá Cerrado MG 1494, a produtividade variou entre 40,55 e 47,67 sacas ha ${ }^{-1}$. No entanto, em Capelinha, houve a formação de quatro grupos distintos, dos quais o mais produtivo foi formado pelas cultivares Catuaí Vermelho IAC 15 e IAC 99 e Catuaí Amarelo IAC 30 e IAC 62, com produtividade entre 42,09 e 47,81 sacas ha-1.

Observa-se que, de maneira geral, em todos locais estudados, as cultivares tiveram boa produtividade. Em Três Pontas, nota-se uma superioridade de pelo menos $21,6 \%$ da produtividade do 'Catuaí Vermelho

Tabela 2. Análise de variância de produtividade de 20 cultivares de café arábica cultivados em Minas Gerais.

\begin{tabular}{lcc}
\hline Fonte de variação & GL & Quadrado médio \\
\hline Bloco/locais (B) & 9 & 50,3362 \\
Progênie (P) & 19 & $469,8581^{* *}$ \\
Locais (L) & 2 & $9.380,1025^{* *}$ \\
P x L & 38 & $358,0565^{* *}$ \\
Erro a & 171 & 71,8780 \\
Biênio (Bi) & 2 & $27.138,0875^{* *}$ \\
Lx Bi & 4 & $808,3418^{* *}$ \\
Erro b & 18 & 448,5644 \\
Px Bi & 38 & $110,5528^{* *}$ \\
Px L x Bi & 76 & $84,3309^{* *}$ \\
Erro c & 342 & 55,1892 \\
\hline Média & & 34,66 \\
CV (\%) & & 21,43 \\
\hline
\end{tabular}

** Significativo a $1 \%$ pelo teste $\mathrm{F}$.
IAC 72', em relação à testemunha de melhor desempenho, Iapar 59. Em Capelinha, a 'Catuaí Vermelho IAC $15^{\prime}$ teve produtividade $26,8 \%$ maior que a cultivar Rubi MG 1192, testemunha de maior produtividade, o que evidencia que neste local houve o maior desempenho produtivo em comparação às testemunhas. Assim, Carvalho et al. (2006), ao avaliar a produtividade de progênies de Catuaí nesses mesmos locais, observaram grande potencial produtivo, embora algumas cultivares tenham-se sobressaído na região de Campos Altos, o que indica a interação genótipoambiente.

O potencial produtivo dessas cultivares também foi relatado por outros autores. Dias et al. (2005), avaliaram a produtividade de cultivares de C. arabica, selecionadas em Minas Gerais, e obtiveram destaque para a cultivar Catuaí Vermelho IAC 99. No Estado de São Paulo, Martins et al. (1992), analisaram progênies de Catuaí, Caturra e Mundo Novo, em Pindorama, e verificaram que o grupo de progênies de Catuaí Amarelo foi $32,8 \%$ mais produtivo que o Mundo Novo. Segundo Verma et al. (1978), um genótipo ideal é aquele que apresenta alta produtividade, associada à alta estabilidade em ambientes desfavoráveis, e é capaz de responder satisfatoriamente a ambientes favoráveis. A identificação desses genótipos é um dos principais objetivos dos programas de melhoramento (Gomes et al., 2007). Na média geral das seis colheitas, as cultivares que tiveram maior produtividade foram: Catuaí Vermelho IAC 15, IAC 72, IAC 99 e Catuaí Amarelo IAC 62, IAC 30, com produtividade entre 38,67 e 41,13 sacas ha-1 (Tabela 3).

Houve efeito significativo para a classificação de peneira 17 e acima de 17 (percentagem de peneira alta) (Tabela 4). Nota-se a formação de dois grupos, em que apenas as cultivares Catuaí Vermelho IAC 100, Catuaí Amarelo IAC 86, Rubi MG 1192 e Catuaí Vermelho IAC 144 apresentaram superioridade sobre as demais (Tabela 3). A classificação por peneiras é indicada por ser uma característica relacionada aos padrões de qualidade do produto. Giomo et al. (2004) avaliaram os efeitos do beneficiamento, em máquina de ventiladores, peneiras e mesa densimétrica, sobre a qualidade de sementes de café Catuaí Amarelo, e verificaram que as sementes pequenas, retidas na peneira 13/64 polegadas, e as sementes de baixa densidade, oriundas da descarga inferior da mesa densimétrica, eram de qualidade fisiológica inferior à das sementes graúdas e pesadas. Assim também, Giomo et al. (2008) verificaram que 
as sementes da cultivar Catuaí Amarelo IAC 62, de maior tamanho ou maior densidade, são de qualidade fisiológica superior à das sementes de menor tamanho ou menor densidade.

$\mathrm{Na}$ análise da percentagem de frutos chochos, observou-se baixa ocorrência de "lojas vazias", com uma amplitude de variação de $2,0 \%$ a 9,5\%. Não foram detectadas diferenças significativas entre as cultivares (Tabela 4). Segundo Carvalho et al. (2006), percentual acima de $90 \%$ de frutos bem granados é considerado satisfatório pelos melhoristas, durante a avaliação e seleção de cafeeiros em programa de melhoramento, visto que grande parte das cultivares comerciais apresentam este percentual. No presente trabalho, todas as cultivares tiveram baixo percentual de frutos chochos, e o menor valor para essa característica foi apresentado pela 'Catuaí Amarelo IAC 17' com percentual de frutos granados de $90,5 \%$.

A divergência entre os grupos formados em cada local justifica o estudo da estabilidade e da adaptabilidade pela metodologia de Annichiarico (1992). Os ambientes constituídos das combinações de Três Pontas - biênio 3, Campos Altos - biênios 2 e 3 e Capelinha - biênios 2 e 3, obtiveram maiores médias e foram classificados como favoráveis (Tabela 5).

Algumas cultivares se destacaram com valores do índice de confiança $\left(\mathrm{I}_{\mathrm{i}}\right)$ geral acima de 100 , e são as mais indicadas para cultivo, com destaque para a Catuaí Vermelho IAC 15, seguida das cultivares Catuaí Amarelo IAC 17, Catuaí Amarelo IAC 30, Catuaí Amarelo IAC 47, Catuaí Amarelo IAC 62, Catuaí Vermelho IAC 72, Catuaí Amarelo IAC 86 e Catuaí Vermelho IAC 99 que obtiveram os valores de $I_{i}$ de 112,04, 100,34, 108,36, 106,10 109,54, 107,77, 101,60 e 105,40, respectivamente (Tabela 6).

De acordo com a metodologia de Annicchiarico (1992), a cultivar de melhor comportamento no presente trabalho, Catuaí Vermelho IAC 15, será, com $75 \%$ de confiança, $12,04 \%$ mais produtiva do que a média do ambiente na condição mais adversa, e com os menores riscos de possuir comportamento abaixo da média do ambiente.

Tabela 3. Produtividade de grãos de 20 cultivares de café arábica, por local e conjunta, e tamanho de grãos medidos pela percentagem de grãos retidos em peneira acima de $17^{(1)}$.

\begin{tabular}{|c|c|c|c|c|c|}
\hline \multirow[t]{2}{*}{ Cultivar } & \multicolumn{3}{|c|}{ Produtividade de grãos $\left(\right.$ sacas ha $\left.^{-1}\right)$} & \multirow[t]{2}{*}{ Média } & \multirow{2}{*}{$\begin{array}{c}\text { Grãos retidos } 17^{(2)} \\
(\%)\end{array}$} \\
\hline & Três Pontas & Campos Altos & Capelinha & & \\
\hline Catuaí Vermelho IAC 15 & $32,20 \mathrm{~b}$ & $43,37 \mathrm{a}$ & $47,81 \mathrm{a}$ & $41,13 a$ & $22,03 \mathrm{~b}$ \\
\hline Catuaí Amarelo IAC 17 & $31,83 b$ & $41,35 \mathrm{a}$ & $33,25 b$ & $35,48 b$ & $27,91 \mathrm{~b}$ \\
\hline Catuaí Amarelo IAC 30 & $29,36 b$ & $42,27 \mathrm{a}$ & $47,14 \mathrm{a}$ & $39,59 \mathrm{a}$ & $31,20 \mathrm{~b}$ \\
\hline Catuaí Vermelho IAC 44 & $25,33 \mathrm{c}$ & $43,03 \mathrm{a}$ & $28,39 \mathrm{c}$ & $33,56 \mathrm{c}$ & $27,65 b$ \\
\hline Catuaí Amarelo IAC 47 & $29,41 b$ & $43,45 \mathrm{a}$ & $39,36 b$ & $37,41 \mathrm{~b}$ & $28,02 b$ \\
\hline Catuaí Vermelho IAC 51 & $24,15 \mathrm{c}$ & $47,67 \mathrm{a}$ & $34,60 \mathrm{~b}$ & $35,47 \mathrm{~b}$ & $31,13 b$ \\
\hline Catuaí Amarelo IAC 62 & $30,59 b$ & $43,73 a$ & $42,09 \mathrm{a}$ & $38,80 \mathrm{a}$ & $33,19 b$ \\
\hline Catuaí Vermelho IAC 72 & $41,10 \mathrm{a}$ & $39,97 b$ & $34,94 b$ & $38,67 \mathrm{a}$ & $27,68 b$ \\
\hline Catuaí Amarelo IAC 79 & $28,90 \mathrm{~b}$ & $33,85 b$ & $39,35 \mathrm{c}$ & $30,70 \mathrm{~d}$ & $31,13 b$ \\
\hline Catuaí Vermelho IAC 81 & $21,34 \mathrm{c}$ & $38,77 \mathrm{~b}$ & $34,66 b$ & $31,59 \mathrm{~d}$ & $28,82 b$ \\
\hline Catuaí Amarelo IAC 86 & $28,31 \mathrm{~b}$ & $43,29 \mathrm{a}$ & $38,19 b$ & $35,59 \mathrm{~b}$ & $36,90 \mathrm{a}$ \\
\hline Catuaí Amarelo IAC 91 & $23,90 \mathrm{c}$ & $38,31 \mathrm{~b}$ & $28,61 \mathrm{c}$ & $30,27 d$ & $30,04 \mathrm{~b}$ \\
\hline Catuaí Vermelho IAC 99 & $29,53 b$ & $41,26 a$ & $45,25 \mathrm{a}$ & $38,68 \mathrm{a}$ & $27,05 b$ \\
\hline Catuaí Vermelho IAC 100 & $26,12 \mathrm{c}$ & $40,55 \mathrm{a}$ & $37,43 b$ & $34,70 \mathrm{c}$ & $35,01 \mathrm{a}$ \\
\hline Catuaí Vermelho IAC 144 & $24,11 \mathrm{c}$ & $46,84 a$ & $28,58 \mathrm{c}$ & $33,18 \mathrm{c}$ & $44,07 \mathrm{a}$ \\
\hline IAPAR 59 & $32,19 b$ & $35,81 \mathrm{~b}$ & $26,25 \mathrm{c}$ & $31,42 d$ & $25,78 b$ \\
\hline Rubi MG 1192 & $29,91 b$ & $37,60 \mathrm{c}$ & $35,00 \mathrm{~b}$ & $34,17 \mathrm{c}$ & $40,51 \mathrm{a}$ \\
\hline Topázio MG 1190 & $34,11 \mathrm{~b}$ & $35,17 b$ & $30,04 \mathrm{c}$ & $33,10 \mathrm{c}$ & $22,30 b$ \\
\hline Mundo Novo IAC 502-9 & $20,09 \mathrm{c}$ & $41,75 \mathrm{a}$ & $23,23 \mathrm{~d}$ & $28,32 \mathrm{~d}$ & $27,86 \mathrm{~b}$ \\
\hline Acaiá Cerrado MG 1474 & $31,23 b$ & $41,10 \mathrm{a}$ & $18,62 \mathrm{~d}$ & $30,32 \mathrm{~d}$ & $29,09 \mathrm{~b}$ \\
\hline Média & 28,68 & 41,16 & 34,13 & 34,66 & 30,37 \\
\hline
\end{tabular}


$\mathrm{Na}$ análise da 'Catuaí Vermelho IAC 15' em relação a 'Mundo Novo IAC 502-9', que obteve o menor índice de confiança do ensaio $(73,65 \%)$, nota-se que houve aumento na confiabilidade de 38,39\%. Ou seja, ao comparar os desempenhos das duas cultivares nos ambientes mais desfavoráveis para cada uma, a Catuaí Vermelho IAC 15 produzirá 38,39\% mais do que 'Mundo Novo IAC 502-9'.

As cultivares Catuaí Vermelho IAC 15, Catuaí Amarelo IAC 17, Catuaí Amarelo IAC 47, Catuaí Amarelo IAC 30, Catuaí Amarelo IAC 62 e Catuaí Vermelho IAC 72 tiveram índice de confiança

Tabela 4. Análise de variância do percentual de frutos chochos (QMF) e de grãos de peneira (QMP) acima de 17 nas safras 2007/2008 e 2008/2009, em Três Pontas, MG.

\begin{tabular}{lccc}
\hline Fonte de variação & GL & QMF & QMP \\
\hline Bloco/locais (B) & 3 & 14,6216 & 87,7379 \\
Progênie (P) & 19 & 13,4936 & $119,6390^{*}$ \\
Erro & 57 & 14,6061 & 54,7793 \\
\hline Média & & 5,79 & 30,38 \\
CV (\%) & 65,94 & 24,36 \\
\hline
\end{tabular}

*Significativo a $5 \%$ de probabilidade, pelo teste $\mathrm{F}$. acima de 100, tanto em ambientes favoráveis como desfavoráveis e se mostraram adaptadas para as duas situações de cultivo. Essas cultivares, com exceção da Catuaí Amarelo IAC 47 e Catuaí Amarelo IAC 17, se mostraram promissoras porque além da maior

Tabela 5. Produtividade de grãos $\left(\mathrm{kg} \mathrm{ha}^{-1}\right)$ de café, por ambiente e índice de qualidade ambiental $\left(\mathrm{I}_{\mathrm{j}}\right)$ estimados pelo método de Annicchiarico (1992), em ensaios de competição de cultivares em três regiões de Minas Gerais.

\begin{tabular}{lcrc}
\hline Ambiente $^{(1)}$ & Média & \multicolumn{1}{c}{$\mathrm{Ij}$} & Classe $^{(2)}$ \\
\hline Três Pontas (biênio 1) & 20,18 & $-14,48$ & Desfavorável \\
Três Pontas (biênio 2) & 27,12 & $-7,54$ & Desfavorável \\
Três Pontas (biênio 3) & 38,76 & 4,10 & Favorável \\
Campos Altos (biênio 1) & 29,44 & $-5,22$ & Desfavorável \\
Campos Altos (biênio 2) & 43,90 & 9,22 & Favorável \\
Campos Altos (biênio 3) & 50,14 & 15,47 & Favorável \\
Capelinha (biênio 1) & 19,79 & $-14,86$ & Desfavorável \\
Capelinha (biênio 2) & 39,22 & 4,56 & Favorável \\
Capelinha (biênio 3) & 43,40 & 8,72 & Favorável \\
\hline
\end{tabular}

(1)Biênio 1, safras 2003/2004 e 2004/2005; biênio 2, safras 2005/2006 e 2006/2007; biênio 3, safras 2007/2008 e 2008/2009. (2)Classes: valores do índice ambiental (Ij), superiores ou iguais a zero, indicam ambientes favoráveis, e negativos indicam ambientes desfavoráveis.

Tabela 6. Estimativa do índice de confiança $\left(\mathrm{I}_{\mathrm{i}}\right)$, segundo o método proposto por Aninicchiarico (1992), para a característica produtividade média de grãos de café beneficiado (sacas de $60 \mathrm{~kg} \mathrm{ha}^{-1}$ ), em três classes de ambiente ${ }^{(1)}$.

\begin{tabular}{|c|c|c|c|c|c|c|c|c|c|}
\hline \multirow[t]{2}{*}{ Cultivar } & \multicolumn{3}{|c|}{$Y_{i}(\%)$} & \multicolumn{3}{|c|}{$\mathrm{S}_{\mathrm{i}}$} & \multicolumn{3}{|c|}{$I_{i}(\%)$} \\
\hline & $\mathrm{AG}$ & $\mathrm{AF}$ & $\mathrm{AD}$ & $\mathrm{AG}$ & $\mathrm{AF}$ & $\mathrm{AD}$ & AG & $\mathrm{AF}$ & $\mathrm{AD}$ \\
\hline Catuaí Vermelho IAC 15 & 41,12 & 52,36 & 27,08 & 23,74 & 27,94 & 19,89 & 112,04 & 115,10 & 107,85 \\
\hline Catuaí Amarelo IAC 17 & 35,47 & 43,74 & 25,14 & 8,85 & 4,05 & 13,51 & 100,34 & 100,55 & 100,46 \\
\hline Catuaí Amarelo IAC 30 & 39,59 & 50,86 & 25,49 & 20,44 & 24,11 & 15,22 & 108,36 & 112,72 & 103,09 \\
\hline Catuaí Vermelho IAC 44 & 33,58 & 41,03 & 24,27 & 17,83 & 14,80 & 23,28 & 91,09 & 90,07 & 91,93 \\
\hline Catuaí Amarelo IAC 47 & 37,40 & 46,42 & 26,13 & 8,74 & 11,07 & 6,29 & 106,10 & 104,96 & 107,40 \\
\hline Catuaí Vermelho IAC 51 & 35,47 & 44,08 & 24,70 & 16,36 & 19,76 & 13,89 & 97,15 & 96,20 & 97,85 \\
\hline Catuaí Amarelo IAC 62 & 38,80 & 47,07 & 28,47 & 14,36 & 17,47 & 9,25 & 109,54 & 104,79 & 115,81 \\
\hline Catuaí Vermelho IAC 72 & 38,67 & 47,00 & 28,24 & 21,84 & 22,55 & 23,45 & 107,77 & 104,13 & 111,62 \\
\hline Catuaí Amarelo IAC 79 & 30,70 & 37,84 & 21,77 & 14,14 & 10,64 & 19,37 & 85,17 & 84,70 & 85,51 \\
\hline Catuaí Vermelho IAC 81 & 31,60 & 40,00 & 21,09 & 15,75 & 17,59 & 14,96 & 85,88 & 87,95 & 82,87 \\
\hline Catuaí Amarelo IAC 86 & 36,60 & 45,83 & 25,04 & 14,44 & 11,23 & 19,64 & 101,60 & 103,22 & 99,24 \\
\hline Catuaí Amarelo IAC 91 & 30,27 & 37,87 & 20,78 & 13,45 & 7,22 & 20,11 & 82,77 & 85,99 & 79,05 \\
\hline Catuaí Vermelho IAC 99 & 38,68 & 50,36 & 24,07 & 17,76 & 19,04 & 11,75 & 105,40 & 112,70 & 97,50 \\
\hline Catuaí Vermelho IAC 100 & 34,70 & 44,05 & 23,00 & 11,03 & 6,52 & 15,60 & 96,83 & 100,61 & 92,40 \\
\hline Catuaí Vermelho IAC 144 & 33,17 & 42,03 & 21,77 & 15,49 & 17,28 & 13,89 & 89,23 & 92,35 & 85,16 \\
\hline IAPAR 59 & 31,42 & 37,37 & 23,97 & 20,93 & 14,95 & 27,53 & 86,34 & 82,51 & 91,36 \\
\hline Rubi MG 1192 & 34,16 & 43,30 & 22,74 & 13,00 & 16,89 & 6,45 & 94,78 & 96,50 & 93,08 \\
\hline Topázio MG1190 & 33,10 & 38,02 & 26,94 & 22,07 & 19,27 & 18,63 & 93,97 & 83,70 & 108,72 \\
\hline Mundo Novo IAC 502-9 & 28,32 & 35,56 & 19,28 & 20,81 & 23,44 & 20,40 & 73,65 & 74,26 & 72,10 \\
\hline Acaiá Cerrado MG 1474 & 30,31 & 36,45 & 22,64 & 27,69 & 32,20 & 24,81 & 79,31 & 74,53 & 84,53 \\
\hline
\end{tabular}

(1)Nível de significância adotado $\alpha=0,25$. $Y_{\mathrm{i}}$, média da progênie i em percentagem; $\mathrm{S}_{\mathrm{i}}$, desvio-padrão dos valores percentuais; $\mathrm{I}_{\mathrm{i}}$, índice de confiança (\%). $\mathrm{AG}$, ambiente geral; $\mathrm{AF}$, ambiente favorável; e $\mathrm{AD}$, ambiente desfavorável. 
estabilidade nos ambientes, ficaram entre as mais produtivas na média dos ambientes, ou seja, aliam estabilidade com alta média de produtividade.

As cultivares Catuaí Amarelo IAC 86, Catuaí Vermelho IAC 99 e Catuaí Vermelho IAC 100 tiveram melhor desempenho em condições favoráveis. A cultivar Topázio MG 1190 mostrou-se ser adaptada para ambientes desfavoráveis (Tabela 6).

As diferenças na adaptabilidade e estabilidade podem ser atribuídas às variações edafoclimáticas dos locais e climáticas dos biênios, utilizados para a formação dos ambientes (Carvalho et al, 2008b; Botelho et al., 2010; Gichimu \& Omondi, 2010).

\section{Conclusões}

1. As cultivares Catuaí Vermelho IAC 15, Catuaí Amarelo IAC 30, Catuaí Amarelo IAC 62 e Catuaí Vermelho IAC 72 são as mais promissoras nas regiões cafeeiras do Estado de Minas Gerais, pois aliam estabilidade e adaptabilidade à alta média de produtividade em ambiente favoráveis e desfavoráveis.

2. As cultivares Catuaí Vermelho IAC 100, Catuaí Amarelo IAC 86, Rubi MG 1192 e Catuaí Vermelho IAC 144 tem maiores percentuais de grãos de peneira alta.

3. Todas as progênies de café arábica testadas neste trabalho apresentam baixa percentagem de frutos chochos.

\section{Agradecimentos}

Ao Conselho Nacional de Desenvolvimento Científico e Tecnológico, ao Consórcio Brasileiro de Pesquisa e Desenvolvimento do Café e à Fundação de Amparo à Pesquisa do Estado de Minas Gerais, pelo suporte financeiro.

\section{Referências}

ANDRADE, A.C. de; MELO, B. de; PAULA, R.C. Avaliação de linhagens das cultivares de cafeeiro Catuaí Vermelho e Amarelo, em solos sob vegetação de Cerrado, do Município de Uberlândia, MG. Horizonte Científico, v.1, p.1-16, 2007.

ANNICCHIARICO, P. Cultivar adaptation and recommendation from alfalfa trials in Northern Italy. Journal of Genetic and Breeding, v.46, p.269-278, 1992.

ANTUNES FILHO, H.; CARVALHO, A. Melhoramento do cafeeiro: ocorrência de lojas vazias em frutos de café Mundo Novo. Bragantia, v.13, p.165-179, 1954.
BONOMO, P.; CRUZ, C.D.; VIANA, J.M.S.; PEREIRA, A.A.; OLIVEIRA, V.R. de.; CARNEIRO, P.C.S. Avaliação de progênies obtidas de cruzamentos de descendentes do 'Híbrido de Timor' com as cultivares Catuaí Vermelho e Catuaí amarelo. Bragantia, v.63, p.207-219, 2004.

BOTELHO, C.E.; MENDES, A.N.G.; CARVALHO, G.R.; BARTHOLO, G.F.; CARVALHO, S.P. Seleção de progênies $F_{4}$ de cafeeiros obtidas pelo cruzamento de 'Icatu' com 'Catimor'. Revista Ceres, v.57, p.274-281, 2010.

BRASIL. Ministério da Agricultura, Pecuária e Abastecimento. Instrução normativa $\mathrm{n}^{-} \mathrm{8}$, de 11 de junho de 2003. Aprova o regulamento técnico de identidade e de qualidade para a classificação do café beneficiado grão cru. Diário Oficial [da] República Federativa do Brasil, 13 jun. 2003. Seção 1, p.4.

CARGNIN, A.; SOUZA, M.A. de; CARNEIRO, P.C.S.; SOFIATTI,V. Interação entre genótipos e ambientes e implicações em ganhos com seleção em trigo. Pesquisa Agropecuária Brasileira, v.41, p.987-993, 2006.

CARVAlHO, A.M. de; PEREIRA, A.A.; CARVAlHO, G.R.; MENDES, A.N.G.; BOTELHO, C.E. Avaliação de progênies de cafeeiros obtidas do cruzamento entre 'Catuaí e 'Híbrido de Timor'. Scientia Agraria, v.9, p.249-253, 2008 b.

CARVALHO, G.R.; BARTHOLO, G.F.; MENDES, A.N.G.; NOGUEIRA, Â.M.; MAGALHÃES M.M. Seleção de progênies oriundas do cruzamento entre 'Catuaí' e 'Mundo Novo' em diferentes regiões do Estado de Minas Gerais. Bragantia, v.65, p.583-590, 2006.

CARVAlHO, G.R.; BOtElHO, C.E.; BARTHOLO, G.F.; PEREIRA, A.A.; NOGUEIRA, A.M.; CARVALHO, A.M. de. Comportamento de progênies $\mathrm{F}_{4}$ obtidas por cruzamentos de 'Icatu' com 'Catimor'. Ciência e Agrotecnologia, v.33, p.47-52, 2009.

CARVALHO, G.R.; GUERREIRO FILHO, O.; PEREIRA, A.A.; ALMEIDA, S.R. de; MATIELO, J.B.; BARTOLO, G.F.; SERA, T.; MOURA, W. de M.; MENDES, A.N.G.; REZENDE, J.C. de; FONSECA, A.F.A. da; FERRÃO, M.A.G.; FERRÃO, R.G.; NACIF, A. de. P.; SILVAROLLA, M.B. Cultivares de café arábica. In: CARVALHO, C.H.S. de. (Ed.). Cultivares de café: origem, características e recomendações. Brasília: Embrapa Café, 2008a. v.1, p.33-55.

CORREA, L.V.T.; MENDES, A.N.G.; BARTHOLO, G.F. Comportamento de progênies de cafeeiro 'Icatu'. Ciência e Agrotecnologia, v.30, p.618-622, 2006.

CRUZ, C.D. Programa Genes: biometria. Viçosa: UFV, 2006. $382 \mathrm{p}$.

CUCOLOTTO, M.; PIPOLO, V.C.; GARBUGLIO, D.D.; FONSECA JUNIOR, N. da S.; DESTRO, D.; KAMIKOGA, M.K. Genotype $\mathrm{x}$ environment interaction in soybean: evaluation through three methodologies. Crop Breeding and Applied Biotechnology, v.7, p.270-277, 2007.

DIAS, F.P.; SOUZA, C.A.S.; MENDES, A.N.G.; CARVALHO, S.P. de; RAZO, B.M.; BOTELHO, C.E. Caracterização de progênies do cafeeiro (Coffea arabica L.) selecionadas em Minas Gerais: II caracteres relacionados à produção. Ceres, v.52, p.85-100, 2005.

FERREIRA, D.F. SISVAR: um programa para análises e ensino de estatística. Revista Symposium, v.6, p.36-41, 2008. 
GICHIMU, B.M.; OMONDI, C.O. Early performance of five newly developed lines of Arabica Coffee under varying environment and spacing in Kenya. Agriculture and Biology Journal of North America, v.1, p.32-39, 2010.

GIOMO, G.S.; NAKAGAWA, J.; GALLO, P.B. Beneficiamento de sementes de café e efeitos na qualidade fisiológica. Bragantia, v.67, p.1011-1020, 2008.

GIOMO, G.S.; RAZERA, L.F.; GALLO, P.B. Beneficiamento e qualidade de sementes de café arábica. Bragantia, v.63, p.291-297, 2004.

GOMES, L. de R.; SANTOS, R.C. dos; FILHO, C.J. da A.; MELO FILHO, P. de A. Adaptabilidade e estabilidade fenotípica de genótipos de amendoim de porte ereto. Pesquisa Agropecuária Brasileira, v.42, p.985-989, 2007.

LIN, C.S.; BINNS, M.R. A method of analysing cultivars x location $\mathrm{x}$ year experiments: new stability parameter. Theoretical and Applied Genetics, v.76, p.425-430, 1988.

MARTINS, A.L.M.; PEROSO, P.A.C.; FAZUOLI, L.C.; GONÇALVES, W. Avaliação de progênies de cafés 'Catuaí Amarelo' e 'Catuaí Vermelho' na região de Pindorama (SP). Bragantia, v.51, p.31-38, 1992.

MELO, B. de; MARCUZZO, K.V.; TEODORO, R.E.F. Avaliação de linhagens de cafeeiro, cultivar Catuaí, em Uberlândia, MG. Ceres, v.53, p.614-618, 2006.

NASCIMENTO, M.; FERREIRA, A.; FERRÃO, R.G.; CAMPANA, A.C.M.; BHERING, L.L.; CRUZ, C.D.; FERRÃO,
M.A.G.; FONSECA, A.F.A. da. Adaptabilidade e estabilidade via regressão não paramétrica em genótipos de café. Pesquisa Agropecuária Brasileira, v.45, p.41-48, 2010.

REIS, P.R.; CUNHA, R.L. da. Café arábica: do plantio à colheita. Lavras: EPAMIG, 2010. 896p.

SILVA, F.L. da; SOARES, P.C.; CARGNIN, A.; SOUZA, M.A. de; SOARES, A.A.; CORNÉLIO, V.M. de O.; REIS, M. de S. Methods of adaptability and stability analysis in irrigated rice genotypes in Minas Gerais, Brazil. Crop Breeding and Applied Biotechnology, v.8, p.119-126, 2008.

VASCONCELOS, E.S. de; REIS, M.S.; CRUZ, C.D.; SEDIYAMA, T.; SCAPIM, C.A. Adaptability and stability of semilate and late maturing soybean genotypes in Minas Gerais state. Acta Scientiarum. Agronomy, v.32, p.411-415, 2010.

VENCOVSKY, R.; BARRIGA, P. Genética biométrica aplicada no fitomelhoramento. Ribeirão Preto: Sociedade Brasileira de Genética, 1992. 496p.

VERMA, M.M.; CHAHAL, G.S.; MURTY, B.R. Limitations of conventional regression analysis: a proposed modification. Theoretical and Applied Genetics, v.53, p.89-91, 1978.

WAMATU, J.N.; THOMAS, E.; PIEPHO, H.P. Responses of different arabica coffee (Coffea arabica L.) clones to varied environment conditions. Euphytica, v.129, p.175-182, 2003.

YAN, W.K.; HUNT, L.A.; SHENG, Q.; SZLAVNICS, Z. Cultivar evaluation and mega-environment investigation based on the GGE biplot. Crop Science, v.40, p.597-605, 2000.

Recebido em 17 de agosto de 2010 e aprovado em 12 de novembro de 2010 